\title{
A Study on China's Deleveraging and Financial Stability Under the Background of Financial Globalization
}

\author{
Zhimin Zhang $^{1} \&$ Xin $\mathrm{Kai}^{1}$ \\ ${ }^{1}$ School of Economics, Central University of Finance and Economics, Beijing, China \\ Correspondence: Xin Kai, School of Economics, Central University of Finance and Economics, Beijing 102206, \\ China. Tel: 086-136-8116-9036. E-mail: kaixin@email.cufe.edu.cn
}

Received: May 6, 2021

doi:10.5539/ijef.v13n8p8
Accepted: June 21, 2021

Online Published: July 8, 2021

\begin{abstract}
This paper studies the impact of financial globalization and leverage ratio on China's financial stability. After the 2008 financial crisis, maintaining the stability of the financial system is China's core task. However, due to the increasing degree of China's opening up policy, the risk of foreign shock is increasing. Meanwhile the domestic policy of deleverage is implemented, so the superposition of domestic and foreign situations aggravates the uncertainty of financial stability. Therefore, this paper selects the relevant variables to empirically study the real impact of financial globalization and leverage ratio on China's financial stability through VAR model. The results show that the indicators of financial stability are most affected by their own inertia, and the deepening of financial globalization and the increasing of leverage ratio will have a positive effect on financial stability at the beginning, but in the later stage it fluctuates a lot. Based on the findings, the China government should put more emphasis on dealing with the relationship between leverage ratio, foreign risks and financial stability when making domestic financial policies.
\end{abstract}

Keywords: financial globalization, leverage ratio, financial stability, VAR model

\section{Introduction}

After the 2008 global financial crisis, governments have paid more attention to the stability of the financial system. As the largest developing country, in order to maintain sustainable development, financial stability has become an inevitable requirement of China. However, this task is faced with both foreign and domestic challenges. From the foreign side, with the development of economic globalization and the deepening of China's economic opening up policy, China is increasingly affected by the international spillover effect brought by the United States, etc. The relationship between financial openness and stability needs to be balanced. At home, due to the stock market disaster in 2015 and in order to prevent systemic financial risks, China began to implement the policy of reducing the financial leverage ratio, but excessive deleveraging will also lead to the slowdown and instability of development.

Under the background of China's policies of financial system opening up and domestic deleveraging, how to maintain financial stability and sustainable development at the same time is a problem worthy of study. Therefore, on the basis of relevant literature and theory, this paper will study the real impact of financial openness and leverage ratio on China's financial stability through empirical methods. The following parts are as follows: the second part is the literature review, the third part introduces the estimation method, model setting and variable selection, the fourth part is the analysis of empirical results, and the fifth part is the conclusion.

\section{Literature Review}

\subsection{The Concept and Measure of Financial Stability}

On the concept of financial stability, Crockett (1996) defines financial instability as abnormal fluctuations in the price of financial assets or the ability of financial intermediaries, thus disturbing the normal operation of the economic system. Creel et al. (2015) points out that financial stability means that the financial system can smoothly resist the impact, and on the macro level, it shows no financial crisis or minimize the impact of the crisis; on the micro level, it shows to reduce the possibility of bankruptcy of financial institutions.

In the quantitative analysis of financial stability, Levine et al. (2000) takes the occurrence of financial crisis as the proxy variable of financial stability. The higher the probability of financial crisis, the worse the financial 
stability. He and Lou (2011) calculates the financial stability index by giving different weights to the deviation of financial institutions, financial markets, external shocks and macroeconomic conditions from the long-term average through principal component analysis.

\subsection{Financial Globalization and Financial Stability}

The literature mainly discusses the promotion and challenge of financial globalization to financial stability. Lane (2013) finds that, the rapid growth of cross-border financial transactions in the past decade caused the rapid expansion of the credit market is the initial stage of the 2008 crisis, and financial globalization has exacerbated the information asymmetry and externality in this process, making the cost of international cooperation in crisis prevention and governance greater. Nicolo and Juvenal (2014) uses the dynamic panel model of 48 emerging markets and developed countries from 1985 to 2008, and found that financial globalization will enhance the quality of cooperative governance and financial institutions, disperse risks, and allocate resources more effectively, resulting in higher output, lower volatility, and reduce the probability of sudden recession of the real economy.

\subsection{Leverage Ratio and Financial Stability}

On the impact of leverage ratio on financial stability, Bouis et al. (2013) finds that most countries begin to reduce leverage ratio after the financial crisis, but if they reduce assets rather than holding or increasing stocks, and financial institutions reduce loans to enterprises, it would reduce the demand of enterprises and households, thus aggravating credit risk and economic recession. Ji et al. (2017) analyzes the connotation and relationship of macro and micro leverage ratio in China through MM theorem, and finds that the determinants of leverage ratio structure and level are very complex: high leverage ratio may cause systemic financial risk, but the risk threshold of leverage ratio level is not stable due to the difference of debt sustainability.

The literature on financial stability, globalization and leverage ratio is relatively sufficient, but there is less research on the compound situation of China's current financial opening and domestic deleveraging. What's more, because the superposition effect of financial opening and deleveraging on financial stability is not clear and needs further research. Therefore, we will analyze the actual impact of financial globalization and leverage ratio on China's financial stability through empirical methods.

\section{Estimation Method, Model Setting and Variable Selection}

\subsection{Estimation Method}

This paper will use vector autoregression model(VAR). VAR model does not focus on the explanation of estimated parameters, but studies the dynamic relationship among multiple variables through impulse response and variance decomposition. The general form of VAR model is as follows,

$$
y_{t}=A_{1} y_{t-1}+\cdots+A_{p} y_{t-p}+B_{1} x_{t}+\cdots+B_{r} x_{t-r}+\varepsilon_{t}
$$

Where, $y_{t}, x_{t}$ is the vector of endogenous and exogenous variables respectively, $p$ and $r$ are the order of lag, $\varepsilon_{t}$ is a random perturbation term. The equation shows that in VAR system, endogenous variable is determined by its own lag term and exogenous variables and their lag terms at the same time.

\subsection{Model Setting}

This paper mainly studies the influence of financial globalization and leverage ratio on financial stability. Therefore, financial stability is taken as the explained variable and the model will be set as follows.

$$
S_{t}=A_{0}+\sum_{p=1}^{n} A_{1 p} S_{t-p}+\sum_{r=0}^{n} A_{2 r} G_{t-r}+\sum_{s=0}^{n} A_{3 s} L_{t-s}+\varepsilon_{t}
$$

In the equation above, $S$ represents the financial stability, $G$ represents the financial globalization, $L$ represents the leverage ratio, and $\varepsilon$ is the disturbance term. The subscript $t$ is time, $p, r$ and $s$ are the lag order of financial stability, financial globalization and leverage ratio, $A_{0}$ is a constant term, $A_{1 p}, A_{2 r}$ and $A_{3 s}$ is the coefficient matrix to be estimated.

\subsection{Variable Selection and Data Description}

\subsubsection{Financial Stability}

Referring to He and Lou (2011), this paper selects four indicators to measure the stability of China's financial system.

Firstly, from the perspective of macroeconomy, we select the inflation rate, that is, the year-on-year growth rate of consumer price index (recorded as CPI). The higher the inflation rate is, the lower the purchasing power of consumers and the lower the confidence of investors will be and lead to the macroeconomic downturn and the 
instability of the financial system. Secondly, from the perspective of financial development, the ratio of the total market value of Shanghai and Shenzhen stock to GDP (recorded as SEC) is selected, which can reflect the development of China's securities market. Thirdly, from the perspective of the steady operation of the banking industry, the 7-day interbank offered rate (recorded as CR7) is selected, which reflects the cost of interbank offered and measures the ability of banks to cope with risks and liquidity level. Fourthly, from the perspective of resisting external risks, we select the foreign exchange reserve rate, that is, the ratio of China's foreign exchange reserves to GDP (recorded as FER). Sufficient foreign exchange reserves will help to stabilize the exchange rate and prevent international financial shocks.

\subsubsection{Financial Globalization}

Referring to Lane (2013), this paper selects the ratio of foreign direct investment to GDP (recorded as FDI) and the ratio of total export trade to GDP (recorded as TR) to represent the actual financial opening indicators of capital flow. FDI and TR reflect the openness of capital and trade respectively, which is an important embodiment of a country's participation in financial globalization.

\subsubsection{Leverage Ratio}

Referring to Ma and Chen (2017), this paper selects the ratio of broad money stock to GDP (recorded as M2) to measure China's leverage ratio. As the main components of M2 are short-term credits such as cash, current deposits, etc, M2 measures the macro leverage level from the perspective of financial institutions' liabilities.

All data are monthly data, and we select the data from January 1998 to March 2018 because of the availableness of the data and the deleveraging progress. The data of GDP, FDI, total stock market value, national interbank offered rate and foreign exchange reserve are from the CEIC database, and the rest are from the National Bureau of Statistics of China.

\section{Empirical Results}

This paper constructs 4 VAR models with CPI, SEC, CR7 and FER as dependent variables respectively, and FDI, TR and M2 as independent variables. As VAR model must satisfy some assumptions, it should be tested before further analysis.

\subsection{Variable Stationarity Test}

Financial variables usually have a certain time trend, which will lead to estimation errors. In this paper, we use the augmented Dickie-Fuller test (ADF) to test the stationarity of the seven variables. Except for inter-bank interest rate, foreign direct investment share and trade share, other variables are non-stationary, but the first-order differences of all variables are stationary. Therefore, all variables are treated by first order difference " $D$ " in the VAR model.

\subsection{Determination of Lag Order}

According to AIC and SIC criteria, the lag order of the 4 VAR models, with CPI, SEC, CR7 and FER as dependent variables, is determined to be 4 .

\subsection{Stability Test of VAR Model}

Before impulse response and variance decomposition analysis, it is necessary to test the stability of VAR model. The main method is unit root test, that is, the reciprocal of all unit root modules of VAR model is less than 1. As shown in Figure 1, the unit roots of VAR models are all in the unit circle, which means that the 4 VAR models are stable.

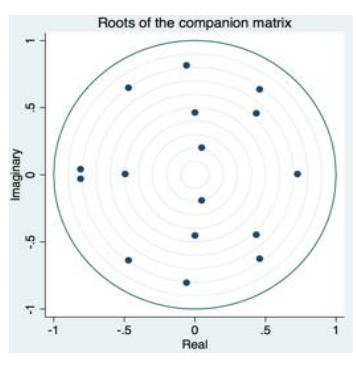

a. CPI as dependent variable

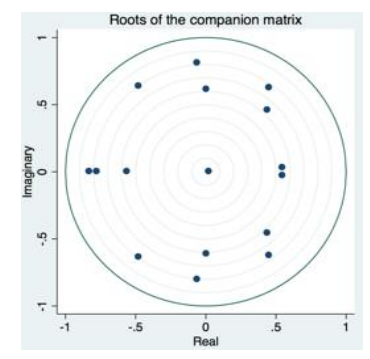

b. SEC as dependent variable

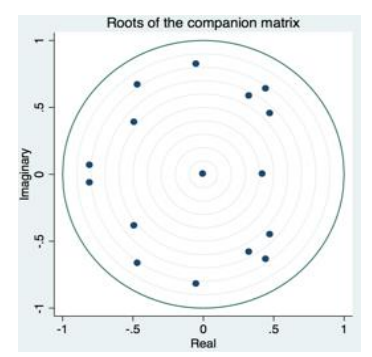

c. CR7 as dependent variable

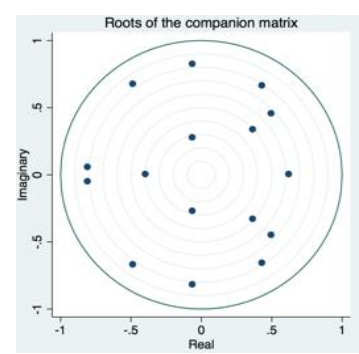

d. FER as dependent variable

Figure 1. Stability test of VAR model 


\subsection{Impulse Response Analysis}

Impulse response describes the impact on the current and future values of all endogenous variables after a standard deviation impact is imposed on the random error . Figure 2.a-2.p shows the results. The horizontal axis represents the impact time (month), the vertical axis represents the response of each variable to a standard deviation innovation impact, and the shaded part is the $95 \%$ confidence interval. According to these results, we analyze the impact of financial globalization and leverage ratio on financial stability from three aspects.

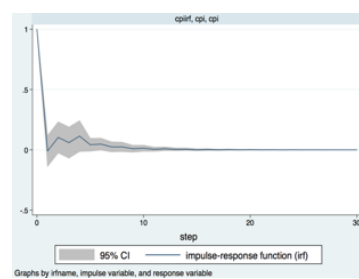

a. $\mathrm{CPI}$ responses to $\mathrm{CPI}$

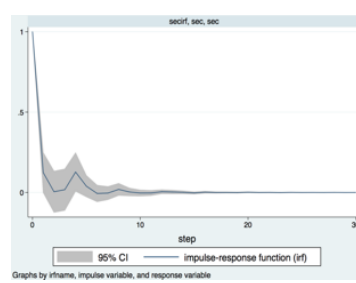

e. SEC responses to SEC

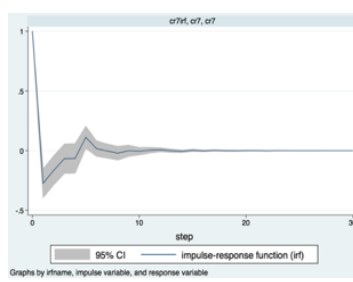

i. $\mathrm{CR} 7$ responses to $\mathrm{CR} 7$

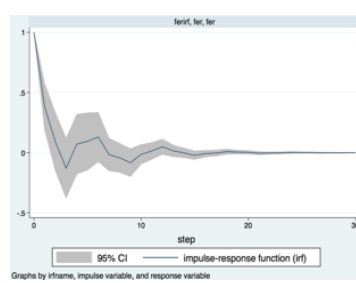

m. FER responses to FER

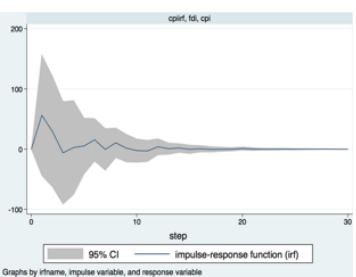

b. CPI responses to FDI

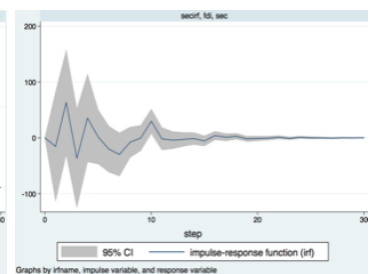

f. SEC responses to FDI

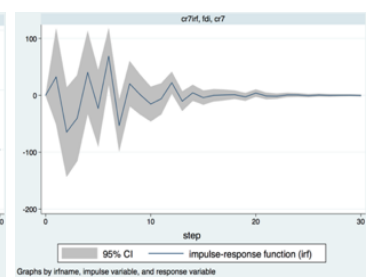

j. CR7 responses to FDI

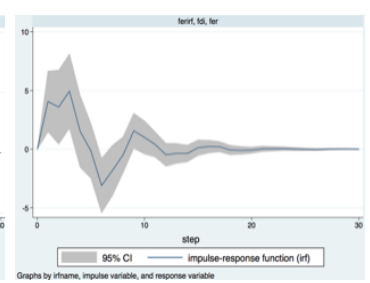

n. FER responses to FDI

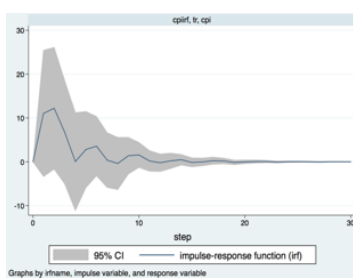

c. CPI responses to TR

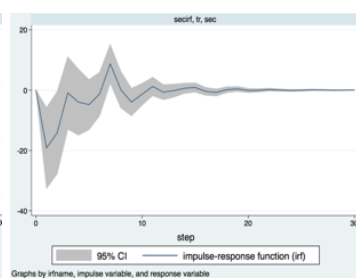

g. SEC responses to TR

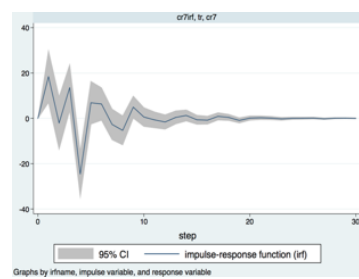

k. CR7 responses to TR

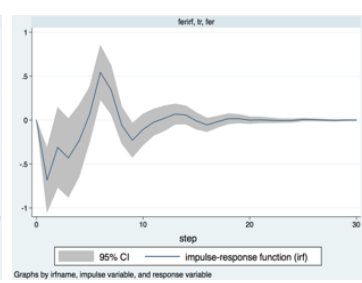

o. FER responses to TR

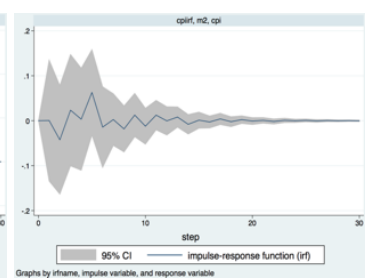

d. CPI responses to M2

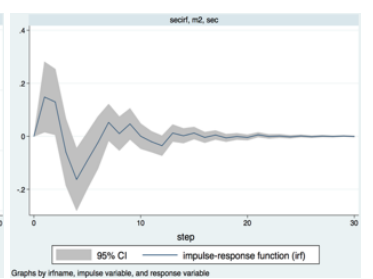

h. SEC responses to M2

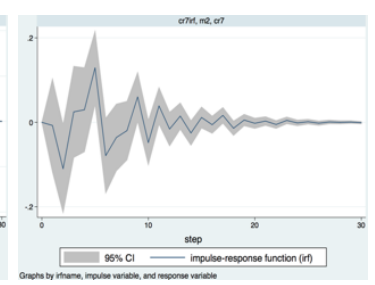

1. CR7 responses to M2

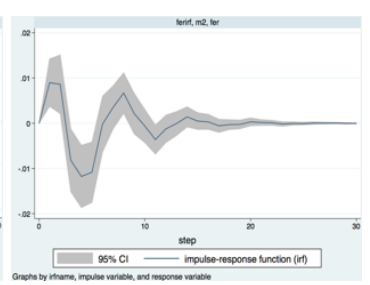

p. FER responses to $\mathrm{M} 2$

Figure 2. Impulse response of the 4 VAR models

First of all, from the perspective of the impact of financial stability variables on themselves, they have the strongest response to their own shocks, especially the fluctuation of foreign exchange reserve rate. The response intensity of other variables gradually tends to be stable after six months. It shows that these variables have obvious inertia in the short term, which is in line with the general economic intuition.

Then, from the perspective of the impact of financial globalization on financial stability. Firstly, FDI and TR have similar impact on CPI, both of which have a positive impact on CPI and fall back and gradually stabilize after reaching the maximum value in the second phase, indicating that the higher the participation of financial globalization, the higher the domestic import inflation rate will be in the short term. Secondly, the impact of FDI and TR on SEC. FDI has a positive impact on SEC at the beginning of the period, and then has a negative impact. SEC's response to TR is on the contrary, indicating that the impact of international trade on the securities market due to foreign exchange settlement and other reasons has a time lag. However, from the perspective of fluctuation range, China's securities market is greatly affected by financial opening, which reflects that China's securities market is weak in resisting external shocks. Thirdly, the impact of FDI and TR on CR7. FDI has a negative impact on CR7 at the beginning of the period, and fluctuates a lot in the later period, but tends to be 
negative on the whole, indicating that foreign investment can reduce financing costs and contribute to financial stability. CR7's response to TR is positive first and then negative, which shows that the impact of international trade on bank system still lags behind. The impact of the two on CR7 tends to be stable in the 12th period, that is, one year later, and has some fluctuations, indicating that the financial opening does have a shock on the stability of the bank system in the short term. Fourthly, the impact of FDI and TR on FER. FDI has a positive impact on FER at the beginning of the period and then turns negative, indicating that foreign direct investment has increased foreign exchange reserves, but there may be capital flight in the later period, and international trade is still stagnant. Generally speaking, the deepening of financial globalization can not only push up inflation in the short term, but also promote the stability of security markets, bank system and foreign exchange reserves, but also have some fluctuations.

Finally, from the perspective of the impact of leverage ratio on financial stability, the response of leverage ratio to CPI is first suppressed and then increased, which indicates that the increase of leverage will push up inflation, but there is a lag effect. The effect of leverage ratio on the security markets will expand the scale of the market at the beginning. However, due to the high risk brought by leverage ratio, the scale of the security markets will drop sharply in the fourth period and stabilize after a small fluctuation in the eighth period. The leverage ratio has the greatest impact on the bank system. At the beginning, due to the increase of the leverage ratio, the borrowing cost will decrease. However, due to the aggravation of the risk, the cost will increase, and the fluctuates a lot in a long period, and it tends to be stable after 20 periods. The impact of leverage ratio on foreign exchange reserve ratio is similar to the situation of rising first and then restraining, with large fluctuation.

\subsection{Analysis of Variance Decomposition}

The variance decomposition analysis of VAR model mainly reveals the proportion of changes caused by the impact of the series itself and other series. The left and right parts of table 1, and the left and right parts of table 2 are the results with CPI, SEC, CR7 and FER as dependent variables respectively.

Table 1. Variance decomposition with CPI and SEC as dependent variables

\begin{tabular}{cccccccccc}
\hline lag order & CPI & FDI & TR & M2 & lag order & SEC & FDI & TR & M2 \\
\hline $\mathbf{1}$ & 0.98 & 0.01 & 0.01 & 0.00 & 1 & 0.95 & 0.00 & 0.03 & 0.02 \\
$\mathbf{2}$ & 0.97 & 0.01 & 0.02 & 0.00 & 2 & 0.92 & 0.00 & 0.04 & 0.03 \\
$\mathbf{3}$ & 0.97 & 0.01 & 0.02 & 0.00 & 3 & 0.92 & 0.01 & 0.04 & 0.03 \\
$\mathbf{4}$ & 0.97 & 0.01 & 0.02 & 0.00 & 4 & 0.90 & 0.01 & 0.04 & 0.05 \\
$\mathbf{5}$ & 0.97 & 0.01 & 0.02 & 0.00 & 5 & 0.89 & 0.01 & 0.05 & 0.06 \\
$\mathbf{6}$ & 0.96 & 0.01 & 0.02 & 0.01 & 6 & 0.89 & 0.01 & 0.05 & 0.06 \\
$\mathbf{7}$ & 0.96 & 0.01 & 0.02 & 0.01 & 7 & 0.88 & 0.01 & 0.05 & 0.06 \\
$\mathbf{8}$ & 0.96 & 0.01 & 0.02 & 0.01 & 8 & 0.88 & 0.01 & 0.05 & 0.06 \\
$\mathbf{9}$ & 0.96 & 0.01 & 0.02 & 0.01 & 9 & 0.88 & 0.01 & 0.05 & 0.06 \\
$\mathbf{1 0}$ & 0.96 & 0.01 & 0.02 & 0.01 & 10 & 0.88 & 0.01 & 0.05 & 0.06 \\
\hline
\end{tabular}

Table 2. Variance decomposition with CR7 and FER as dependent variables

\begin{tabular}{cccccccccc}
\hline lag order & CR7 & FDI & TR & M2 & lag order & FER & FDI & TR & M2 \\
\hline $\mathbf{1}$ & 0.96 & 0.00 & 0.04 & 0.00 & 1 & 0.92 & 0.02 & 0.04 & 0.03 \\
$\mathbf{2}$ & 0.93 & 0.02 & 0.03 & 0.01 & 2 & 0.88 & 0.03 & 0.04 & 0.05 \\
$\mathbf{3}$ & 0.92 & 0.02 & 0.05 & 0.01 & 3 & 0.84 & 0.05 & 0.04 & 0.06 \\
$\mathbf{4}$ & 0.87 & 0.02 & 0.10 & 0.01 & 4 & 0.81 & 0.05 & 0.04 & 0.10 \\
$\mathbf{5}$ & 0.85 & 0.02 & 0.10 & 0.03 & 5 & 0.79 & 0.04 & 0.04 & 0.12 \\
$\mathbf{6}$ & 0.84 & 0.02 & 0.11 & 0.03 & 6 & 0.77 & 0.05 & 0.06 & 0.12 \\
$\mathbf{7}$ & 0.83 & 0.03 & 0.11 & 0.03 & 7 & 0.77 & 0.05 & 0.06 & 0.12 \\
$\mathbf{8}$ & 0.83 & 0.03 & 0.11 & 0.03 & 8 & 0.76 & 0.05 & 0.06 & 0.13 \\
$\mathbf{9}$ & 0.82 & 0.03 & 0.11 & 0.04 & 9 & 0.76 & 0.05 & 0.06 & 0.13 \\
$\mathbf{1 0}$ & 0.82 & 0.03 & 0.11 & 0.04 & 10 & 0.76 & 0.05 & 0.06 & 0.13 \\
\hline
\end{tabular}

It can be drawn from table 1 and table 2 that, firstly, the four dependent variables have the greatest influence on itself, which is consistent with the results of impulse response. Secondly, the impact of international trade on financial stability is greater than that of foreign investment, which is consistent with the current situation of 
China's control of capital account. The degree of financial globalization has the greatest impact on the bank system, and the impact on foreign exchange reserves, security markets and inflation is weakening in turn. Thirdly, leverage ratio has the largest long-term impact on the foreign exchange market and its explanatory power is gradually increasing, while its impact on the security markets, bank system and inflation is weakening in turn, which may be due to the strong linkage between the broad money supply and a country's foreign exchange reserves.

\section{Conclusions}

From the results of the empirical study, we can draw the following conclusions: firstly, from the perspective of indicators of financial stability, these variables are most affected by themselves. Secondly, financial globalization promotes financial stability at the beginning, but there is a rebound risk at the later stage, and international trade has a lag effect. Thirdly, leverage ratio also promotes financial stability at the beginning, but fluctuates greatly in the later period. Fourthly, financial globalization has the strongest explanatory power to the fluctuation of banking operation robustness, and the explanatory power of other aspects is similar to leverage ratio.

Generally speaking, the deepening of financial globalization and the increasing of leverage ratio will have a positive effect on financial stability at the beginning, but it will fluctuate greatly later. It is a long-term task to prevent systemic risks and ensure financial stability. We need to consider multi-dimensional factors to balance the relationship among financial openness, deleveraging and financial stability.

This study contributes to the existing literatures by combing the financial globalization and deleveraging progress, which could be defied as foreign risk and domestic risk related to the financial stability issues that the China government is faced with into a unified framework, so as we could point out the real effect brought by the two tasks. Understanding the real effect not only helps the China government to make the financial policies properly, but also is a useful supplement to the existing theories.

\section{References}

Bouis, R., Christensen, A. K., \& Cournede, B. (2013). Deleveraging: Challenges, Progress and Policies. OECD Economics Department Working Papers, No.1077. https://doi.org/10.1787/5k4221459fjc-en

Creel, J., Hubert, P., \& Labondance, F. (2015). Financial Stability and Economic Performance. Economic Modelling, 48(35), 25-40. https://doi.org/10.1016/j.econmod.2014.10.025

Crockett, A. (1996). The Theory and Practice of Financial Stability. De Economist, 144(4), 531-568. https://doi.org/10.1007/BF01371939

He, D. X., \& Lou, F. (2011). The Measurement and Analysis of Index of China's Financial Stability. Journal of Graduate School of Chinese Academy of Social Sciences, 4, 16-25. https://doi.org/CNKI:SUN:ZSKY.0.2011-04-007

Ji, M., Yan, B. Y., \& Li, H. J. (2017). Leverage Structure, Level and Financial Stability: Theory and Empirics. Journal of Financial Research, 2, 11-25. https://doi.org/CNKI:SUN:JRYJ.0.2017-02-002

Lane, P. R. (2013). Financial Globalization and the Crisis. Open Economies Review, 24(3), 555-580. https://doi.org/10.1007/s11079-012-9266-0

Levine, R., Loayza, N., \& Beck, T. (2000). Financial Intermediation and Growth: Causality and Causes. Journal of Monetary Economics, 46(1), 31-77. https://doi.org/10.1016/S0304-3932(00)00017-9

Ma, Y., \& Chen, Y. L. (2017). Financial Leverage, Leverage Volatility and Economic Growth. Economic Research Journal, 6, 31-45. https://doi.org/CNKI:SUN:JJYJ.0.2017-06-004

Nicolo, G. D., \& Juvenal, L. (2014). Financial Integration, Globalization and Real Activity. Journal of Financial Stability, 10(1), 65-75. https://doi.org/10.1016/j.jfs.2013.04.004

\section{Copyrights}

Copyright for this article is retained by the author(s), with first publication rights granted to the journal.

This is an open-access article distributed under the terms and conditions of the Creative Commons Attribution license (http://creativecommons.org/licenses/by/4.0/). 